\title{
Body Size as a Driver of Scavenging in Theropod Dinosaurs
}

\author{
Adam Kane, ${ }^{1, \star}$ Kevin Healy, ${ }^{2, \star}, \dagger$ Graeme D. Ruxton, ${ }^{3}$ and Andrew L. Jackson ${ }^{2,}$ \\ 1. School of Biological, Earth and Environmental Sciences, Cooperage Building, North Mall Campus, University College Cork, Cork, \\ Ireland; 2. School of Natural Sciences, Trinity College Dublin, Dublin 2, Ireland; and Trinity Centre for Biodiversity Research, Trinity \\ College Dublin, Dublin 2, Ireland; 3. School of Biology, University of St Andrews, St Andrews, United Kingdom \\ Submitted June 30, 2015; Accepted January 7, 2016; Electronically published April 12, 2016
}

Online enhancements: appendix. Dryad data: http://dx.doi.org/10.5061/dryad.650c5.

\begin{abstract}
AвsтRACT: Theropod dinosaurs dominated Earth's terrestrial ecosystem as a diverse group of predators for more than 160 million years, yet little is known about their foraging ecology. Maintaining a balanced energy budget presented a major challenge for therapods, which ranged from the chicken-sized Microraptor up to the whalesized Giganotosaurus, in the face of intense competition and the demands of ontogenetic growth. Facultative scavenging, a behavior present in almost all modern predators, may have been important in supplementing energetically expensive lifestyles. By using agentbased models based on the allometric relationship between size and foraging behaviors, we show that theropods between 27 and $1,044 \mathrm{~kg}$ would have gained a significant energetic advantage over individuals at both the small and large extremes of theropod body mass through their scavenging efficiency. These results were robust to rate of competition, primary productivity, and detection distance. Our models demonstrate the potential importance of facultative scavenging in theropods and the role of body size in defining its prevalence in Mesozoic terrestrial systems.
\end{abstract}

Keywords: dinosaurs, scavenging, scaling, body mass, theropods, agent-based models.

\section{Introduction}

For more than 160 million years, theropod dinosaurs dominated Earth's terrestrial ecosystems as a diverse group of apex predators. Given that they include some of the largest terrestrial predators known to have existed, how they fueled their lifestyle has been a topic of debate since their first conception as sluggish reptiles right up to today's image of them as fast-paced hunters (Bakker 1975, 1986; Brusatte et al. 2010). This current view of theropod biology encompasses mesothermic lifestyles (Grady et al. 2014), along with the mechanical and physiological ability to transport large body masses, all of which require large energy inputs.

\footnotetext{
* These authors contributed equally to this work.

† Corresponding author; e-mail: healyke@tcd.ie.

\# ORCIDs: Kane, http://orcid.org/0000-0002-2830-5338; Healy, http://orcid .org/0000-0002-3548-6253; Jackson, http://orcid.org/0000-0001-7334-0434.

Am. Nat. 2016. Vol. 187, pp. 706-716. (C) 2016 by The University of Chicago. 0003-0147/2016/18706-56376\$15.00. All rights reserved.

DOI: $10.1086 / 686094$
}

One way predators may have offset part of this cost is through opportunistic scavenging on the carrion available in such ecosystems.

Practically all modern predators are known to scavenge when the opportunity arises (DeVault et al. 2003), often supplementing relatively large proportions of their energy requirements; for example, studies over multiple years show that jackals, lions, and brown hyenas can acquire up to $20 \%, 50 \%$, and $90 \%$ of their food from opportunistic scavenging, respectively (Mills 1990; Schaller 2009; Benbow et al. 2015). Like modern predators, theropods are also likely to have availed of facultative scavenging. Several dinosaur fossil remains show trace marks indicative of scavenging (Chure et al. 1998; Hone and Rauhut 2010; Hone and Watabe 2010; Longrich et al. 2010), including those of species unlikely to have been killed by the predators involved (Chure et al. 1998; Longrich et al. 2010). While obligate scavenging is largely restricted to low-cost locomotion strategies, such as soaring flight (Ruxton and Houston 2004), and is unlikely to meet the energetic requirements of terrestrial species (Ruxton and Houston 2003, 2004; Carbone et al. 2011), facultative scavenging is still likely to have been an important process in these systems. In particular, the proportion of energy that might have come from scavenging as opposed to active hunting is one of the key unresolved issues in understanding the trophic interactions of Mesozoic systems.

In comparison to modern ecosystems, high primary productivity (Trammer 2011) and unusual body size distributions (O'Gorman and Hone 2012) in Mesozoic systems may have created distinct niches utilized by theropods. Specifically, body size in theropods is likely to have been an important factor determining the ability of predators to access carcasses, as seen in modern scavenging guilds (Wallace and Temple 1987). Body size reflects not only the ability to search large areas (Farlow 1994; Carbone and Gittleman 2002) but also the ability to displace competitors (Kendall 2013; Kane et al. 2014), to break open carcasses (Pomeroy et al. 2011), and to extract larger amounts of food at a single sitting owing to a larger gut capacity (Ruxton and Houston 2004). Indeed, these adaptations are seen among scaveng- 
ing birds, where vultures are among the largest representatives. This allometry would have important consequences in niche partitioning among theropod species but also within species during ontogeny, as is seen across a diversity of extant animals (Steyn 1980; Winemiller 1989; Hirai 2002; Woodward and Hildrew 2002; Platt et al. 2006; Knoff et al. 2008).

Here we build on previous work that typically focused on species in isolation and used purely analytical approaches (Ruxton and Houston 2003) by implementing allometric scaling relationships based on body size within an agentbased model to show that facultative scavenging could have comprised a significant proportion of a theropod's energy requirements. As these foraging traits cannot be tested directly in extinct groups such as theropods, we also extended our model to a well-known extant system to confirm predictions relating to observed levels of scavenging in a range of facultative scavengers and low-cost soaring flight as a requirement for a viable obligate scavenging lifestyle in vultures (Ruxton and Houston 2004). We show that the efficiency of facultative scavenging in theropods is highest at intermediate body sizes independent of carcass density, prey size distributions, theropod thermoregulation, and the ability to detect carcasses, highlighting the role of body size in determining the importance of scavenging in theropods.

\section{Methods}

To estimate the importance of scavenging across a range of theropod body masses, we used allometric equations to parameterize an agent-based model in order to include explicitly the interactions between theropods competing for carcasses. To allow for comparisons across a large range of body sizes, the proportion of searching energy offset through facultative scavenging to the costs of foraging was then calculated by dividing daily energy inputs from scavenging by daily energy costs. A value of one implies scavenging is cost neutral, with the costs of foraging canceling the energetic benefits of scavenging, while values greater than one indicate a surplus of energy and values below one indicate an energy deficit. However, while a value greater than one indicates surplus energy, it may not indicate obligate scavenging as a viable strategy, as such a species would need to acquire enough surplus energy to invest in growth, reproduction, and nonforaging behaviors. Obligate scavenging would thus be feasible only in situations with values far in excess of one.

\section{Allometries and Parameters}

Daily energy expenditure is dependent on both basal metabolic rate and the additional locomotion costs of foraging. For cost of locomotion, we used the estimated values calculated in Pontzer et al. (2009) for nine dinosauriforms ranging from 0.25 to $6,000 \mathrm{~kg}$ (fig. 1). Note that one of the species, Marasuchus, is a dinosaur-like ornithodiran and that the Gorgosaurus is a juvenile (for more details, see Pontzer et al. 2009). We included these to increase the range of body sizes for which we have fossil data. The energetics of locomotion was calculated as the mass-specific cost of transport $(\mathrm{COT} ; \mathrm{J} / \mathrm{kg} / \mathrm{m})$ using the equation COT $=90.284 \times h^{-0.77}$, where $h$ is hip height in centimeters (Pontzer 2007). To calculate the total cost of foraging (COF), COT was multiplied by the mass $(\mathrm{kg})$ and speed $(\mathrm{m} / \mathrm{s})$ of the animal at walking pace. Walking speed was calculated using $\mathrm{Fr}=$ speed $^{2} \times h \times 9.81$, where the Froude number (Fr), which relates to inertial forces due to the effects of gravity, was set at 0.25 to estimate walking speed (Pontzer et al. 2009). In order to investigate the role of scavenging in theropods across a larger range of body sizes than available from the data, we fit a log-log regression between mass and estimated hip heights taken from Pontzer et al. (2009) to calculate COF for a further five body sizes (figs. 1, A1). Using these estimates of COF, we calculated the daily cost of foraging over a 12-h foraging day, following Ruxton and Houston (2003). Daily basal metabolic costs $\left(B \cdot\right.$ day $\left._{i}\right)$ were then calculated using the mesothermic dinosaur allometric relationship $B_{i}=0.002 \times$ mass $_{i}{ }^{0.82}$ from Grady et al. (2014) and converted to units of kilojoules/day to give B.day ${ }_{i}$. The daily energetic cost of each species ( $i$ ) was then calculated as $\mathrm{COF}_{i} \times 0.5+$ B.day $_{i}$.

The energy gained through scavenging is dependent on both the ability to find and consume carcasses and the energy content of those carcasses. The detection distance of theropods was based on the maximum recorded distance at which hyenas can detect a carcass, which is $2,000 \mathrm{~m}$ (Mills 1990), with the less extreme detection distances of 200 and $500 \mathrm{~m}$ modeled separately as sensitivity analyses. To reflect the restrictions imposed by size on the ability to consume large quantities of carcass material, we restricted daily consumption using the allometric scaling of gut capacity, $0.075 \times$ mass $^{0.94}$, as defined for mammals by Calder (1996).

To estimate the energy derived from scavenging, we followed previous studies (Ruxton and Houston 2003; Carbone et al. 2011) by using a figure of $4.38 \mathrm{~kg} / \mathrm{km}^{2} /$ day for carcass production, based on the Serengeti as an analogue for terrestrial Mesozoic systems. We distributed this production rate across herbivore size classes based on the binning approach in Carbone et al. (2011) by using the mass-abundance scaling relationship $N_{\mathrm{h}}=100 \times$ mass $^{-0.75}$, based on data from mammalian herbivore abundances (Damuth 1981). Herbivore body size bins across the Mesozoic were determined using the distribution from O'Gorman and Hone (2012). The carcass production rate was then distributed to each bin based on the abundance of individuals expected in each bin size from the scaling relationship of Carbone 


\begin{tabular}{|c|c|c|c|c|c|}
\hline Species & Mass (kg) & Hip height (cm) & Speed (m/s) & COF (kJ/day) & \\
\hline Archaeopteryx & 0.25 & 13 & 0.6 & 89 & $x^{\prime \prime}$ \\
\hline Marasuchus & 1 & 14 & 0.6 & 306 & \\
\hline Microraptor & 1.2 & 24 & 0.8 & 360 & \\
\hline Coelophysis & 20 & 44 & 1.0 & 4529 & \\
\hline Velociraptor & 20 & 42 & 1.0 & 4582 & \\
\hline Inferred & 100 & - & 1.3 & 19806 & \\
\hline Gorgosaurus & 210 & 100 & 1.6 & 38960 & \\
\hline Dilophosaurus & 430 & 116 & 1.7 & 74957 & \\
\hline Inferred & 1000 & - & 1.7 & 162140 & \\
\hline Allosaurus & 1400 & 149 & 1.9 & 220591 & \\
\hline Inferred & 4000 & - & 2.0 & 576870 & \\
\hline Tyrannosaurus & 6000 & 264 & 2.5 & 836459 & \\
\hline Inferred & 10000 & - & 2.7 & 1336070 & \\
\hline Inferred & 15000 & - & 2.9 & 1937877 & \\
\hline
\end{tabular}

Figure 1: Values for mass $(\mathrm{kg})$, hip height $(\mathrm{cm})$, speed $(\mathrm{m} / \mathrm{s})$, and daily cost of foraging $(\mathrm{COF} ; \mathrm{kJ} /$ day) used in the analysis. Inferred hip estimates were calculated based on regression analysis between species mass and hip heights (fig. A1). Artwork by Kevin Healy.

et al.'s (2011) mass-density calculations. All carcasses were set to decay at a constant rate, lasting 7 days (i.e., one-seventh of the original carcass mass is lost per day), until no tissue was available due to scavenging from mammalian scavengers, invertebrates, bacteria, and so on (Sinclair and NortonGriffiths 1995; Carbone et al. 2011; Gianechini and de Valais 2015).

To include competition in our models, we again followed the approach used by Carbone et al. (2011) of calculating theropod abundances using the size-abundance scaling for mammalian carnivores of $N_{\mathrm{t}}=1.97 \times$ mass $^{-0.88}$ (Carbone and Gittleman 2002). We calculated these abundances for body size bins of 10,100 , and $1,000 \mathrm{~kg}$ to represent the main theropod body sizes across the Mesozoic (O'Gorman and Hone 2012). Given the low abundances of larger forms, such as Tyrannosaurs, our focal individuals represent the total predicted abundances of these species in the simulated environment. Finally, we included the effect of competition at carcasses by allowing larger species to displace and exclude smaller foraging species (fig. 2).

We ran a number of sensitivity analyses to include different body size distributions of both herbivores and theropod competitors reflecting the estimated body size distributions from the Hell Creek Formation (Horner et al. 2011) and the Morrison Formation (O'Gorman and Hone 2012). To account for possible taphonomic bias, we ran a separate analysis with carcasses skewed toward smaller sizes by including a 10-kg body size category in the Generic
Mesozoic body size distribution and recalculating carcass abundances accordingly (Brown et al. 2013). We also ran the main model with a 500-m detection distance and double the carcass production $\left(8.76 \mathrm{~kg} / \mathrm{km}^{2} /\right.$ day $)$ to investigate the possible effects of a higher primary productivity as well as a separate model with competition doubled to investigate the effects of increased competition.

To account for the possibility that larger theropods may have had larger detection ranges, we reran the main model with detection distance scaling to maximum detection distances of 200,500, and 2,000 m, according to the scaling of the olfactory bulb ratio with body mass (Zelenitsky et al. $2009,2011)$. To investigate the effects of allowing individuals to exclude smaller competitors from a carcass site, we also reran the main models without competitor exclusion behaviors. As the nature of theropod metabolism is still a hotly debated topic (D’Emic 2015; Grady et al. 2015; Myhrvold 2015), we also determined the costs of operating under ectothermic and endothermic resting metabolic rates using the fitted body mass scaling from Grady et al. (2015) and estimated field metabolic rates. Field metabolic rates (FMR) were used as simplified approximates of our more complex model as a further step to verify our approach. We used the scaling equation FMR $=4.82 \times$ mass $^{0.734}$ for mammal field metabolic rates (Nagy 2005) and a rough approximate of field metabolic rate for theropods by multiplying the scaling equation from Grady et al. (2015) by three (Nagy 2005). Finally to describe the relationship between 

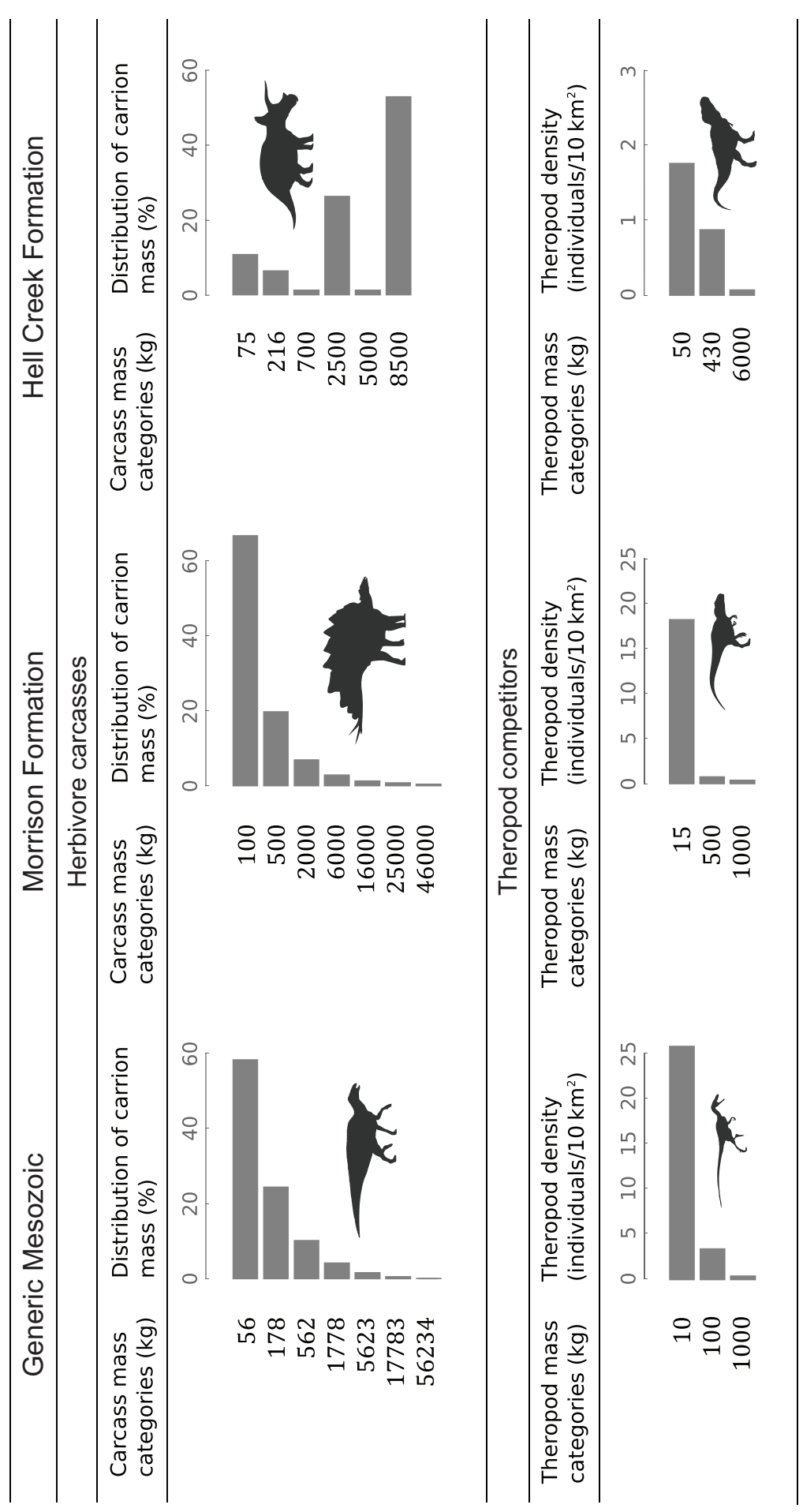

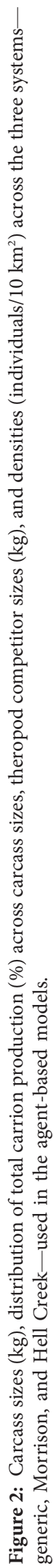

This content downloaded from 138.251.162.200 on May 27, 2016 06:27:04 AM 
body size and the proportion of energy gained to energy expended during foraging, we fit a series of polynomials using general linear models in $\mathrm{R}$ ( $\mathrm{R}$ Development Core Team 2010) and used Akaike information criterion (AIC) for model selection (Crawley 2014).

\section{Agent-Based Model}

We created a spatially explicit agent-based model using the above-calculated parameters to include the effect of competition on the various theropod species. Our model was designed in the program NetLogo (Tisue and Wilensky 2004). The simulation space was a $50 \times 50-\mathrm{km}$ square corresponding to a $2,500 \mathrm{~km}^{2}$ landscape with periodic boundary conditions (individuals moving off one side appeared again instantly on the opposite side and could detect food across this boundary). The model had a series of mobile agent types that corresponded to our focal theropods and a series of competitors (figs. 1, 2).

The initial state of the model had all dinosaurs and carcasses located randomly in the environment. All theropods, both focal and competitors, then set off in a random direction at their assigned speed searching for carrion (fig. 1). They maintained the same walking speed for the duration of the model and had a constant turning rate. On finding a carcass in its visual field (at 200, 500, or 2,000 m away), the animal walked toward it and started to feed, extracting energy until sated, as defined by its gut capacity, or until the carcass was consumed. If nothing remained for the animals to eat and they were not entirely sated, they began to forage again. If full, the animal moved away from the carcass and desisted from further foraging until the next day, whereupon their total gut capacity was restored. The gut passage time of dinosaurs is difficult to ascertain, but we know it was relatively quick for large theropods given the state of consumed material in coprolites (Chin et al. $1998,2003)$. We incorporated competition by having smaller competitors avoid any larger individuals while foraging. A foraging day in our model was $12 \mathrm{~h}$. We ran the model for 375 days, with a 10 -day burn-in to allow carcasses to reach all stages of decomposition before foraging begins.

In total, we ran 16 separate models, including 3 full main models with respective detection distances of 200,500, and 2,000 m; 3 models with detection distances of $500 \mathrm{~m}$ and carcass and competition body size distributions matching, respectively, the Hell Creek Formation, the Morrison Formation, and an inferred habitat with a skew toward smaller carcass sizes; 2 models with a 500-m detection distance-1 with double carcass production and 1 with double competition density; 3 models with scaling detection distances up to maximum ranges of 200,500 , and 2,000 m, respectively; 3 models with no exclusion competition at carcass sites and detection distances of 200,500 , and 2,000 m, respectively; and 2 models with respective ectothermic and endothermic metabolisms with a 500-m detection distance.

\section{Extant Model}

We also created a model for extant systems to determine the effectiveness of this agent-based approach in predicting scavenging efficiencies in better-studied extant species. The model was based on a well-characterized savannah ecosystem in Swaziland (Monadjem et al. 2003) and operates similarly to those built for the theropods. It is comprised of three obligate scavenging species - the African white-backed vulture (Gyps africanus), white-headed vulture (Trigonoceps occipitalis), and lappet-faced vulture (Torgos tracheliotos) — and four facultative scavenging species - the marabou stork (Leptoptilos crumeniferus), bateleur (Terathopius ecaudatus), spotted hyena (Crocuta crocuta), and jackal (Canis mesomelas). There are accurate population estimates for all of these species in Swaziland, aside from the jackal, whose population we estimated from values recorded elsewhere (Monadjem 2003; Monadjem et al. 2003; Klare et al. 2010). We used estimates from the literature to parameterize carcass size distributions, gut capacity, speed, and cost of foraging and body mass (Del Hoyo and Elliot 1994; Nowak 1999; Mukherjee et al. 2004; Ruxton and Houston 2004; Holekamp and Dloniak 2010; Duriez et al. 2014; Kane et al. 2015). We compared the results of this model to the observed level of scavenging for each of these species. Based on previous models (Ruxton and Houston 2004), we expected to see only obligate scavenging, as indicated by scavenging efficiencies far in excess of one, in vulture species modeled based on their highly efficient soaring flight costs. For powered flight, we expected all species to have scavenging efficiencies close to one, but not far in excess below or above, with the bateleur predicted to have a lower efficiency than the marabou stork based on observations taken from Ogada et al. (2012), where marabous arrived at twice the number of experimental carcasses compared to bateleurs. Finally, we expected jackal efficiency to be lower than that of spotted hyenas (Benbow et al. 2015).

\section{Results}

The results of our models show that the proportion of energy gained by scavenging compared to the energy lost during foraging follows a convex pattern across body mass, with a peak of scavenging efficiency approximately corresponding with the size of an adult Dilophosaurus (430 kg; figs. 1, 2, B1-B5; figs. B1-B9 available online).

Energy gained through scavenging accounts for up to $68 \%$ of the energetic cost of foraging in the case of a $430-\mathrm{kg}$ theropod with a $2-\mathrm{km}$ detection distance (fig. 3). The least- 
efficient scavengers occupy the extremes of theropod body size, with a 15-ton individual's scavenging accounting for as little as $8 \%$ of its foraging costs, while a $0.25-\mathrm{kg}$ individual's scavenging accounts for only $14 \%$ (fig. 3). As expected, scavenging efficiencies increase with carcass detection distance, with a $10 \%$ increase in proportional energy gained between foraging with 100 - and 500-m ranges and a $19 \%$ increase between 100- and 2,000-m detection ranges (fig. 3; table B2; tables B1-B3 available online).

While the overall level of scavenging efficiency is dependent on detection distance (fig. 3), carcass size distributions (figs. 4, B1), carcass production rates, and carcass competition rate (fig. 5), for the presence of exclusion behavior at carcass sites (fig. B2), the scaling of visual detection distance with body size (fig. B3), and the thermoregulation strategy employed by the scavengers (fig. B4), or how foraging costs are calculated (fig. B5), a humped pattern described by a cubic polynomial model was found to be the best fit, based on AIC, in all cases (tables B1, B2). This humped pattern is the result of the disparity between the scaling of energetic costs, which scales according to an exponent of 0.91 (table B2), and energy input, which scales according to a cubic polynomial that initially scales according to an exponent of 1.07 but plateaus after 1,000 kg (fig. B6). The log-log linear increase of total energetic costs with body size were mainly due to costs associated with foraging, with basal metabolic rate (BMR) accounting for only a maximum of $14 \%$ at the lowest body mass and decreasing to $0.02 \%$ for the largest theropods (fig. B7). The polynomial behavior of energy input is itself the result of the limitations imposed by gut capacity, which scales according to an exponent of 0.94 on a log-log scale, and the overall availability of carcasses after competition, which scales according to an exponent of 0.15 on a log-log scale (fig. B8; table B2).

The most efficient sizes for scavenging across all models, taken as the maximum of these fitted equations, ranged from 27 to $1,044 \mathrm{~kg}$ across all models, with an average of $428 \mathrm{~kg}$. Systems with left-skewed distributions of carcass size showed the lowest theropod sizes for maximum scavenging efficiency (fig. B1), while systems dominated by larger carcasses, such as the Hell Creek Formation, showed larger body sizes at maximum scavenging efficiency (fig. 4). Maximum scavenging efficiencies ranged from $17 \%$ to $90 \%$ across all models, with high-carcass-productivity scenarios (fig. 5) giving the highest efficiencies. The carcass and competitor distributions of the Hell Creek Formation yielded the lowest maximum scavenging efficiencies (fig. 4; table B2).

When these models were applied to the extant system, they predicted high scavenging efficiencies in all the scavenging species included in the models. Obligate scavenging was predicted to be a viable foraging strategy only in the case of vultures that foraged using soaring flight, with daily foraging costs accounting for as little as 15\% of daily energy costs for these species (table B3). While species modeled using powered flight showed high levels of scavenging efficiency, accounting for up to $98 \%$ of daily forag-

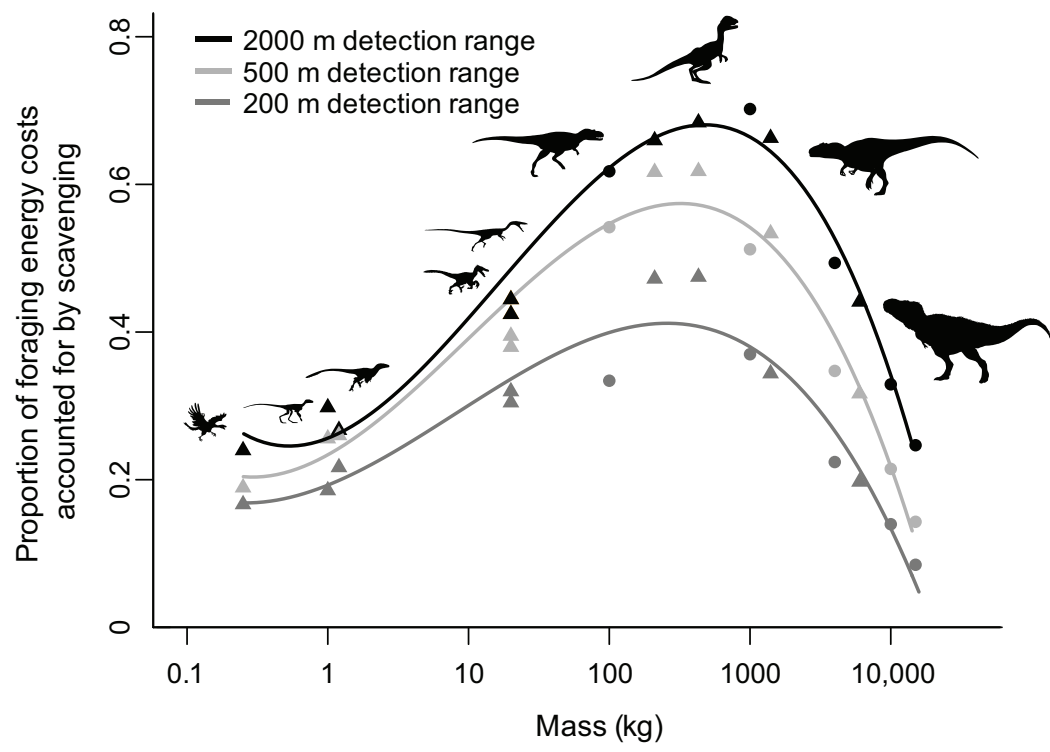

Figure 3: Proportion of daily energy expenditure offset by energy intake from scavenging across body $\operatorname{mass} \log _{10}$ (body mass, $\mathrm{kg}$ ) in our main analysis. Triangles represent species estimates and are, from left to right, Archaeopteryx, Marasuchus, Microraptor, Velociraptor, Coelophysis, Gorgosaurus, Dilophosaurus, Allosaurus, and Tyrannosaurus. Circles represent inferred points based on a regression analysis (fig. A1). The detection ranges are represented by the black $(2,000 \mathrm{~m})$, light gray $(500 \mathrm{~m})$, and dark gray $(200 \mathrm{~m})$ data points and fitted linear models. 


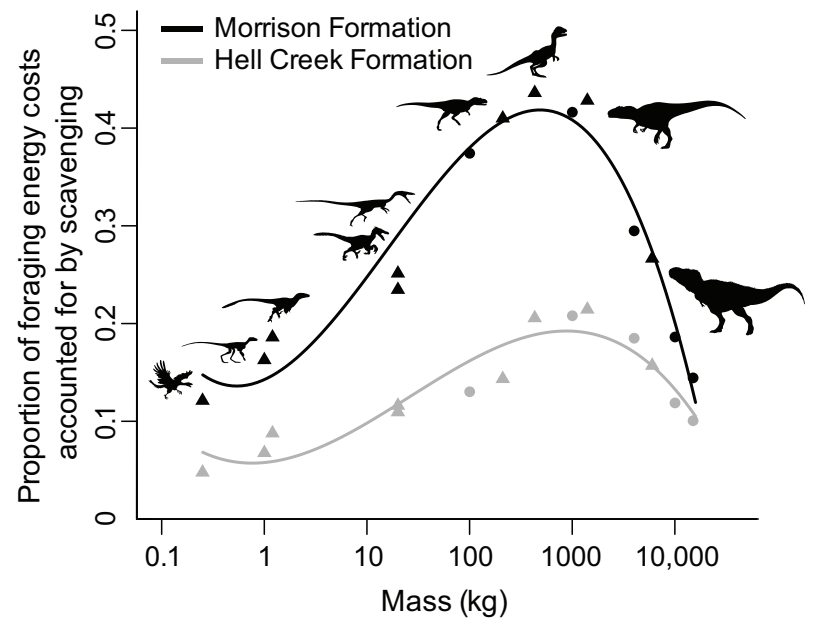

Figure 4: Proportion of daily energy expenditure offset by energy intake from scavenging across body mass $\log _{10}$ (body mass, $\mathrm{kg}$ ) with body size distributions representative of the Hell Creek (gray) and Morrison (black) formations. Triangles represent species estimates and are, from left to right, Archaeopteryx, Marasuchus, Microraptor, Velociraptor, Coelophysis, Gorgosaurus, Dilophosaurus, Allosaurus, and Tyrannosaurus. Circles represent inferred points based on a regression analysis (fig. A1).

ing costs in the intermediately sized African white-backed vulture, all species using this strategy were predicted to be facultative scavengers. As expected, based on observations of scavenging behaviors (Ogada et al. 2012), the bateleur was a less efficient scavenger than the marabou stork (ta- ble B3; fig. B9). Both terrestrial species also showed high efficiencies in scavenging with hyenas, as expected (Benbow et al. 2015), showing a higher level of efficiency than Jackals (table B3). Data are deposited in the Dryad Digital Repository: http://dx.doi.org/10.5061/dryad.650c5 (Kane et al. 2016).

\section{Discussion}

Our results show that facultative scavenging is likely to have played a significant role in Mesozoic terrestrial systems. In particular, we found that theropods between 27 and $1,044 \mathrm{~kg}$ could have gained a significant energetic advantage through opportunistic scavenging. This efficiency of facultative scavenging in intermediately sized theropods reflects the trade-off between the costs and benefits of extreme body size. While theropods of larger sizes can increase the number of scavenging opportunities through higher search rates, gut capacity, and a greater ability to compete at carcasses, the locomotory costs incurred in transporting their large masses outpaces the energetic benefits accrued from searching (fig. B6). This disparity between the cost of foraging and the intake from scavenging appears only at large sizes exceeding $1,000 \mathrm{~kg}$ when energy intake from scavenging plateaus (figs. B6-B8). This plateau is the result of an inability to exploit further scavenging opportunities despite the increased gut capacity and search areas, due to reaching a limitation of carcasses available after competition (fig. B8). In contrast, while smaller individuals have a

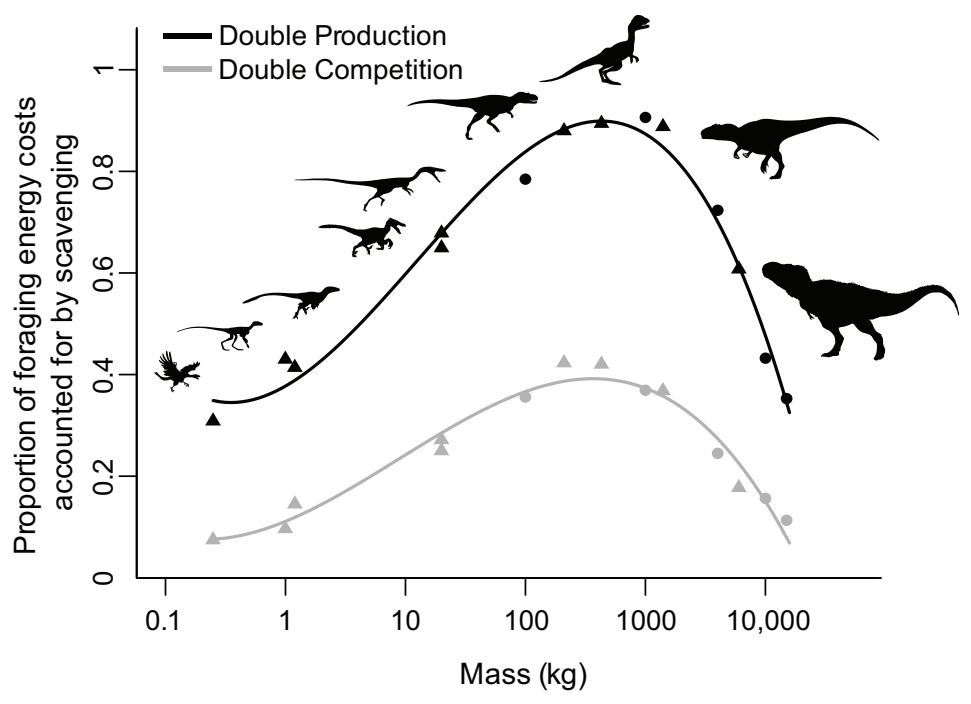

Figure 5: Proportion of daily energy expenditure offset by energy intake from scavenging across body mass (kg) with double the carcass productivity (black) and double the number of theropod competitors (gray). Triangles represent species estimates and are, from left to right, Archaeopteryx, Marasuchus, Microraptor, Velociraptor, Coelophysis, Gorgosaurus, Dilophosaurus, Allosaurus, and Tyrannosaurus. Circles represent inferred points based on a regression analysis (figs. 1, A1). 
lower cost of foraging, they suffer an inability to take advantage of available scavenging opportunities due to constraints imposed by lower gut capacity and, to a lesser degree, lower search rates and an inability to compete at carcasses. Even if we relax these assumptions and consider a lack of competitive exclusion at carcass site or an increase in carrion detection abilities due to larger sensory organs (Zelenitsky et al. 2009, 2011) and an elevated position relative to the ground in larger theropods (Farlow 1994), the convex pattern of scavenging efficiency remains robust (Ruxton and Houston 2004).

The results of our models suggest that both high levels of facultative scavenging and niche partitioning of scavenging with body size are likely to have heavily influenced Mesozoic systems (Codron et al. 2013). In particular, many of the niches in these systems were divided across ontogeny, with extreme disparities between adult and juvenile body sizes (Steyn 1980; Winemiller 1989; Brusatte et al. 2010; Myhrvold 2013). For example, immature individuals of larger species such as Tyrannosaurus would have benefited from coinciding with our predicted maximally efficient sizes for facultative scavenging theropods. This additional energy benefit from scavenging may have allowed such theropods to attain even larger sizes in response to the growth rate of their prey species (Cooper et al. 2008).

While scavenging is likely to have been an important energy source for intermediate-sized individuals, extreme gigantism, such as seen in the adult forms of Tyrannosaurs, Giganotosaurus, and Carcharodontosaurus, are unlikely to have been driven by scavenging behavior, with a specialized hyperpredator role more likely (Brusatte et al. 2010; DePalma et al. 2013). Even when accounting for the ability of larger forms to fast over long periods of food shortage (Lindstedt and Boyce 1985), the net negative energy balance of scavenging in large theropods would eventually lead them to require alternative food sources to scavenging. The idea that ecosystems with certain faunal size distributions, such as Hell Creek (Horner et al. 2011), may have benefitted scavenging in adult Tyrannosaurs was also not supported in our analysis, with our models showing that such an environment would have struggled to meet the full energy requirements of any large scavenging animal. Moreover, many of these unusual body size distributions may in fact reflect a taphonomic bias such that smaller species were not preserved in the fossil record (Brown et al. 2013). In contrast to proposals of scavenging in large theropods, our results fit better to previous suggestions that Dilophosaurus, a midsize theropod in our analysis, was mainly a scavenger due to a jaw morphology unsuited for hunting (Welles 1984). However, according to our models, even $\mathrm{Di}$ lophosaurus is unlikely to have achieved the levels of foraging efficiency required to meet an obligate scavenging exis- tence, with a foraging strategy more similar to modern facultative scavengers such as hyenas a more likely scenario.

Indeed, our approach may prove useful in future studies on scavenging efficiency in extant carnivores. Our extant model was successful in predicting the necessity of soaring flight as a requirement in obligate scavenging in birds (Ruxton and Houston 2004) and in predicting the higher scavenging efficiencies in species with high levels of observed scavenging, such as hyenas and marabou storks, in comparison to species with lower levels of scavenging, such as bateleurs and jackals. Scavenging is becoming more recognized as a vital component of ecosystem structure and functioning (DeVault et al. 2003), with facultative scavengers often taking the role of the main consumers (Moleón et al. 2015). Despite this, scavenging is often omitted from ecological models, and instead all carnivory is considered to be the result of predation (Wilson and Wolkovich 2011). With scavenging estimated to be involved in up to $45 \%$ of food-web links, this is a serious oversight (Wilson and Wolkovich 2011). There are obvious difficulties in determining whether a food item was hunted or scavenged (DeVault et al. 2003), but the importance of the latter behavior underscores the importance of generating more of this data through careful observational fieldwork, stable isotope analysis, and gut content examination.

Historically, the lack of modern analogues to theropod dinosaurs has made it difficult to draw clear conclusions about their mode of life. Yet, with recent advances in paleontology and by using a combination of allometric scaling and agent-based modeling, we can more clearly define their feeding ecology. Our models demonstrate the potential importance of facultative scavenging and of body size in defining its role in Mesozoic terrestrial systems. By using the approaches outlined here and furthering our efforts in understanding the role of scavenging in modern ecosystems by testing for similar patterns in scavenging, we can further our understanding of the dynamics of extinct ecosystems.

\section{Acknowledgments}

We thank several people for useful discussions that have helped develop this article, including C. Carbone, J. Hutchinson, D.-E. Nilsson, and the members of NERD club. We would also like to thank both the editor and reviewers for their suggestions that helped improve the manuscript. This work was funded by the Earth and Natural Sciences Doctoral Studies Programme and the Higher Education Authority through the Programme for Research at Third Level Institutions, Cycle 5 (PRTLI-5), and cofunded by the European Regional Development Fund (K.H.) and Trinity College Dublin and the Irish Research Council (A.K.). 
Finally, to LM, SB, AG, and all others involved: the bet is still on.

\section{APPENDIX A}

Hip Height Estimation and Extant Model Details

\section{Hip Height Estimation}

To include extra estimates of foraging ability for species between and above the range available in the literature, we calculated predicted hip heights based on estimates available for nine species using a regression between the $\log _{10}$ transform of both mass and hip heights. Hip height was strongly correlated with body size (estimate $=0.15, \mathrm{SE}=0.01161$, $P>.001, R^{2}=0.96$; fig. A1). We used this relationship to calculate predicted hip heights for a further five body sizes $(100,1,000,4,000,10,000$, and $15,000 \mathrm{~kg})$, which were then used to calculate, as described in the "Methods" section, walking speed and cost of foraging (fig. 1).

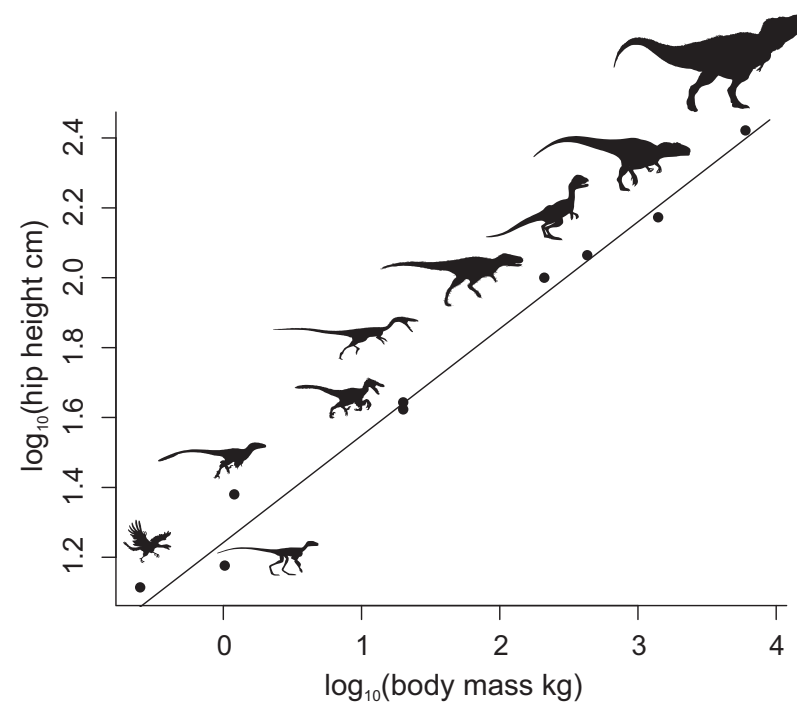

Figure A1: $\log _{10}$ of hip height (cm) against $\log _{10}$ body mass $(\mathrm{kg})$ for nine dinosauriformes (eight theropods and the dinosaur-like ornithodiran Marasuchus). Estimates for mass and hip heights are from Pontzer et al. (2009).

\section{Methods and Parameters for Extant Model}

The model was based on a well-characterized savannah ecosystem in Swaziland (Monadjem et al. 2003). Population estimates from Monadjem et al. (2003) were used for the African white-backed vulture (Gyps africanus), white-headed vulture (Trigonoceps occipitalis), lappet-faced vulture (Torgos tracheliotos), marabou stork (Leptoptilos crumeniferus), bateleur (Terathopius ecaudatus), and spotted hyena (Crocuta crocuta). For the jackal (Canis mesomelas), we estimated population densities from Klare et al. (2010). The Handbook of the Birds of the World was used for body size for bird species (Del Hoyo and Elliot 1994), and Walker's Mammals of the World was used for body size in the jackal and spotted hyena (Nowak 1999). We binned the herbivores that formed the carcasses into two size categories of 55 and $220 \mathrm{~kg}$ because the carrion-forming animals have an approximately bimodal distribution in terms of their body mass (Monadjem et al. 2003). The gut capacity was estimated for each species from Calder (1996). Speed of foraging was based on those used in Ruxton and Houston (2004), with the speed (m/s) that minimized cost of traveling calculated as $V_{\mathrm{fb}}=16 \times$ mass ${ }^{0.14}$ for powered flight, $V_{\mathrm{sb}}=8 \times$ mass $^{0.14}$ for soaring flight, and $V_{\mathrm{m}}=1.15 \times$ mass $^{0.12}$ for terrestrial locomotion in mammals. The cost of locomotion for powered flight $(W)$ was calculated as $S_{\mathrm{fb}}=57 \times$ mass $^{0.83}-3.8 \times$ mass for powered flight and $S_{\mathrm{m}}=0.075 \times$ speed $\times$ mass $^{0.68}$ for terrestrial locomotion (Ruxton and Houston 2004). For soaring flight, energetic costs calculated based on a Eurasian griffon vulture as $S_{\mathrm{sb}}=2.03 \times$ mass (Duriez et al. 2014). Resting metabolic rates were calculated as $R_{\mathrm{b}}=3.8 \times$ mass $^{0.72}$ for birds and $R_{\mathrm{m}}=3.4 \times$ mass $^{0.75}$ for mammals. Detection capabilities for each species were taken from the literature, with the visual range given as $4 \mathrm{~km}$ for aerial species and $0.5 \mathrm{~km}$ for terrestrial species to reflect the relative ease of detecting carrion in-flight. As in the theropod models, daily costs were calculated as daily cost of foraging ${ }_{i} \times 0.5+$ daily cost of resting metabolic rate ${ }_{i}$. The environment of the individual-based model was smaller than the theropod models at $900 \mathrm{~km}^{2}$ to reflect the habitat of Swaziland where these species are encountered (Monadjem et al. 2003). Carcass density and interaction rules are the same as in the theropod models (see "Methods").

\section{Literature Cited}

Bakker, R. T. 1975. Dinosaur renaissance. Scientific American 232: 58-78.

1986. The dinosaur heresies: new theories unlocking the mystery of the dinosaurs and their extinction. Morrow, New York. Benbow, M. E., J. K. Tomberlin, and A. M. Tarone. 2015. Introduction to carrion ecology, evolution, and their applications. Pages 461-494 in M. E. Benbow, J. K. Tomberlin, and A. M. Tarone, eds. Carrion ecology, evolution, and their applications. CRC Press, Boca Raton, Florida.

Brown, C. M., D. C. Evans, N. E. Campione, L. J. O’Brien, and D. A. Eberth. 2013. Evidence for taphonomic size bias in the Dinosaur Park Formation (Campanian, Alberta), a model Mesozoic terrestrial alluvial-paralic system. Palaeogeography, Palaeoclimatology, Palaeoecology 372:108-122.

Brusatte, S. L., M. A. Norell, T. D. Carr, G. M. Erickson, J. R. Hutchinson, A. M. Balanoff, G. S. Beve, J. N. Choiniere, P. J. Makovicky, and X. Xu. 2010. Tyrannosaur paleobiology: new research on ancient exemplar organisms. Science 329:1481-1485. 
Calder, W. A. 1996. Size, function, and life history. Dover, New York. Carbone, C., and J. L. Gittleman. 2002. A common rule for the scaling of carnivore density. Science 295:2273-2276.

Carbone, C., S. T. Turvey, and J. Bielby. 2011. Intra-guild competition and its implications for one of the biggest terrestrial predators, Tyrannosaurus rex. Proceedings of the Roval Societv B: Biological Sciences 278:2682-2690.

Chin, K., D. A. Eberth, M. H. Schweitzer, T. A. Rando, W. J. Sloboda, and J. R. Horner. 2003. Remarkable preservation of undigested muscle tissue within a Late Cretaceous tyrannosaurid coprolite from Alberta, Canada. Palaios 18:286-294.

Chin, K., T. T. Tokaryk, G. M. Erickson, and L. C. Calk. 1998. A king-sized theropod coprolite. Nature 393:680-682.

Chure, D. J., A. R. Fiorillo, and A. Jacobsen. 1998. Prey bone utilization by predatory dinosaurs in the Late Jurassic of North America, with comments on prey bone use by dinosaurs throughout the Mesozoic. Gaia 15:227-232.

Codron, D., C. Carbone, and M. Clauss. 2013. Ecological interactions in dinosaur communities: influences of small offspring and complex ontogenetic life histories. PLoS ONE 8:e77110.

Cooper, L. N., A. H. Lee, M. L. Taper, and J. R. Horner. 2008. Relative growth rates of predator and prey dinosaurs reflect effects of predation. Proceedings of the Roval Society B: Biological Sciences 275: 2609-2615.

Crawley, M. J. 2014. Statistics: an introduction using R. Wiley, West Sussex.

Damuth, J. 1981. Population density and body size in mammals. $\mathrm{Na}$ ture 290:699-700.

Del Hoyo, J., and A. Elliot. 1994. Handbook of the birds of the world. 2. New World vultures to guineafowl. Lynx Edicions, Barcelona.

D'Emic, M. D. 2015. Comment on "Evidence for mesothermy in dinosaurs." Science 348:982.

DePalma, R. A., D. A. Burnham, L. D. Martin, B. M. Rothschild, and P. L. Larson. 2013. Physical evidence of predatory behavior in Tyrannosaurus rex. Proceedings of the National Academy of Sciences of the USA 110:12560-12564.

DeVault, T. L., O. E. Rhodes Jr., and J. A. Shivik. 2003. Scavenging by vertebrates: behavioral, ecological, and evolutionary perspectives on an important energy transfer pathway in terrestrial ecosystems. Oikos 102:225-234.

Duriez, O., A. Kato, C. Tromp, G. Dell'Omo, A. L. Vyssotski, F. Sarrazin, and Y. Ropert-Coudert. 2014. How cheap is soaring flight in raptors? a preliminary investigation in freely-flying vultures. PLoS ONE 9:e84887.

Farlow, J. O. 1994. Speculations about the carrion-locating ability of tyrannosaurs. Historical Biology 7:159-165.

Gianechini, F. A., and S. de Valais. 2015. Bioerosion trace fossils on bones of the Cretaceous South American theropod Buitreraptor gonzalezorum Makovicky, Apesteguía and Agnolín, 2005 (Deinonychosauria). Historical Biology, http://dx.doi.org/10.1080/08912963.2014.991726.

Grady, J. M., B. J. Enquist, E. Dettweiler-Robinson, N. A. Wright, and F. A. Smith. 2014. Evidence for mesothermy in dinosaurs. Science 344:1268-1272.

. 2015. Response to comments on "Evidence for mesothermy in dinosaurs." Science 348:982.

Hirai, T. 2002. Ontogenetic change in the diet of the pond frog, Rana nigromaculata. Ecological Research 17:639-644.

Holekamp, K. E., and S. M. Dloniak. 2010. Intraspecific variation in the behavioral ecology of a tropical carnivore, the spotted hyena. Advances in the Study of Behavior 42:189-229.
Hone, D. W., and O. W. Rauhut. 2010. Feeding behaviour and bone utilization by theropod dinosaurs. Lethaia 43:232-244.

Hone, D. W., and M. Watabe. 2010. New information on scavenging and selective feeding behaviour of tyrannosaurids. Acta Palaeontologica Polonica 55:627-634.

Horner, J. R., M. B. Goodwin, and N. Myhrvold. 2011. Dinosaur census reveals abundant Tyrannosaurus and rare ontogenetic stages in the Upper Cretaceous Hell Creek Formation (Maastrichtian), Montana, USA. PLoS ONE 6:e16574.

Kane, A., K. Healy, G. D. Ruxton, and A. L. Jackson. 2016. Data from: Body size as a driver of scavenging in theropod dinosaurs. American Naturalist, Dryad Digital Repository, http://dx.doi.org/10.5061 /dryad.650c5.

Kane, A., A. L. Jackson, A. Monadjem, M. A. Colomer, and A. Margalida. 2015. Carrion ecology modelling for vulture conservation: are vulture restaurants needed to sustain the densest breeding population of the African white-backed vulture? Animal Conservation 18:279-286.

Kane, A., A. L. Jackson, D. L. Ogada, A. Monadjem, and L. McNally. 2014. Vultures acquire information on carcass location from scavenging eagles. Proceedings of the Roval Society B: Biological Sciences 281:20141072.

Kendall, C. J. 2013. Alternative strategies in avian scavengers: how subordinate species foil the despotic distribution. Behavioral Ecology and Sociobiology 67:383-393.

Klare, U. N. N., J. F. Kamler, U. T. E. Stenkewitz, and D. W Macdonald. 2010. Diet, prey selection, and predation impact of black-backed jackals in South Africa. Journal of Wildlife Management 74:1030-1041.

Knoff, A., A. Hohn, and S. Macko. 2008. Ontogenetic diet changes in bottlenose dolphins (Tursiops truncatus) reflected through stable isotopes. Marine Mammal Science 24:128-137.

Lindstedt, S. L., and M. S. Boyce. 1985. Seasonality, fasting endurance, and body size in mammals. American Naturalist 125:873-878.

Longrich, N. R., J. R. Horner, G. M. Erickson, and P. J. Currie. 2010. Cannibalism in Tyrannosaurus rex. PLoS ONE 5:e13419.

Mills, M. 1990. Kalahari hyaenas: comparative behavioural ecology of two species, v. 304. Unwin Hyman, London.

Moleón, M., J. A. Sánchez-Zapata, E. Sebastián-González, and N. Owen-Smith. 2015. Carcass size shapes the structure and functioning of an African scavenging assemblage. Oikos 124:1391-1403.

Monadjem, A. 2003. Nesting distribution and status of vultures in Swaziland. Vulture News 48:12-19.

Monadjem, A., R. C. Boycott, V. Parker, and J. Culverwell. 2003 Threatened vertebrates of Swaziland: Swaziland red data book: fishes, amphibians, reptiles, birds and mammals. Swaziland Environment Authority, Ministry of Tourism, Environment and Communications, Mbabane, Swaziland.

Mukherjee, S., S. Goyal, A. Johnsingh, and M. Leite Pitman. 2004. The importance of rodents in the diet of jungle cat (Felis chaus), caracal (Caracal caracal) and golden jackal (Canis aureus) in Sariska Tiger Reserve, Rajasthan, India. Journal of Zoology 262:405-411.

Myhrvold, N. P. 2013. Revisiting the estimation of dinosaur growth rates. PLoS ONE 8:e81917.

2015. Comment on "Evidence for mesothermy in dinosaurs." Science 348:982.

Nagy, K. A. 2005. Field metabolic rate and body size. Journal of Experimental Biology 208:1621-1625.

Nowak, R. M. 1999. Walker's mammals of the world, v. 1. Johns Hopkins University Press, Baltimore. 
Ogada, D., M. Torchin, M. Kinnaird, and V. Ezenwa. 2012. Effects of vulture declines on facultative scavengers and potential implications for mammalian disease transmission. Conservation Biology 26:453-460.

O'Gorman, E. J., and D. W. E. Hone. 2012. Body size distribution of the dinosaurs. PLoS ONE 7:e51925.

Platt, S. G., T. R. Rainwater, A. G. Finger, J. B. Thorbjarnarson, T. A. Anderson, and S. T. McMurry. 2006. Food habits, ontogenetic dietary partitioning and observations of foraging behaviour of Morelet's crocodile (Crocodylus moreletii) in northern Belize. Herpetological Journal 16:281-290.

Pomeroy, D., A. Byaruhangab, G. Kaphu, M. Opige, M. Masiko, and B. Lutuk. 2011. Second count of vultures at carcasses in Uganda, and a revised proposal for a standardised method. Vulture News 60:15-21.

Pontzer, H. 2007. Effective limb length and the scaling of locomotor cost in terrestrial animals. Journal of Experimental Biology 210 1752-1761.

Pontzer, H., V. Allen, and J. R. Hutchinson. 2009. Biomechanics of running indicates endothermy in bipedal dinosaurs. PLoS ONE 4 e7783.

R Development Core Team. 2010. R: a language and environment for statistical computing. R Foundation for Statistical Computing. Vienna, Austria.

Ruxton, G. D., and D. C. Houston. 2003. Could Tyrannosaurus rex have been a scavenger rather than a predator? an energetics approach. Proceedings of the Royal Society B: Biological Sciences 270:731-733.

- 2004. Obligate vertebrate scavengers must be large soaring fliers. Journal of Theoretical Biology 228:431-436.

Schaller, G. B. 2009. The Serengeti lion: a study of predator-prey relations. University of Chicago Press, Chicago.

Sinclair, A. R. E., and M. Norton-Griffiths. 1995. Serengeti: dynamics of an ecosystem. University of Chicago Press, Chicago.
Steyn, P. 1980. Breeding and food of the bateleur in Zimbabwe (Rhodesia). Ostrich 51:168-178.

Tisue, S., and U. Wilensky. 2004. NetLogo: design and implementation of a multi-agent modeling environment. Proceedings of Agent 2004:7-9.

Trammer, J. 2011. Differences in global biomass and energy use between dinosaurs and mammals. Acta Geologica Polonica 61:125132.

Wallace, M. P., and S. A. Temple. 1987. Competitive interactions within and between species in a guild of avian scavengers. Auk 104:290-295.

Welles, S. P. 1984. Dilophosaurus wetherilli (Dinosauria, Theropoda) osteology and comparisons. Palaeontographica Abteilung A 185: 85-180.

Wilson, E. E., and E. M. Wolkovich. 2011. Scavenging: how carnivores and carrion structure communities. Trends in Ecology and Evolution 26:129-135.

Winemiller, K. O. 1989. Ontogenetic diet shifts and resource partitioning among piscivorous fishes in the Venezuelan ilanos. Environmental Biology of Fishes 26:177-199.

Woodward, G., and A. G. Hildrew. 2002. Body-size determinants of niche overlap and intraguild predation within a complex food web. Journal of Animal Ecology 71:1063-1074.

Zelenitsky, D. K., F. Therrien, and Y. Kobayashi. 2009. Olfactory acuity in theropods: palaeobiological and evolutionary implications. Proceedings of the Roval Society B: Biological Sciences 276:667-673

Zelenitsky, D. K., F. Therrien, R. C. Ridgely, A. R. McGee, and L. M. Witmer. 2011. Evolution of olfaction in non-avian theropod dinosaurs and birds. Proceedings of the Royal Society B: Biologica Sciences 278:3625-3634.

Associate Editor: H. Arthur Woods Editor: Alice A. Winn

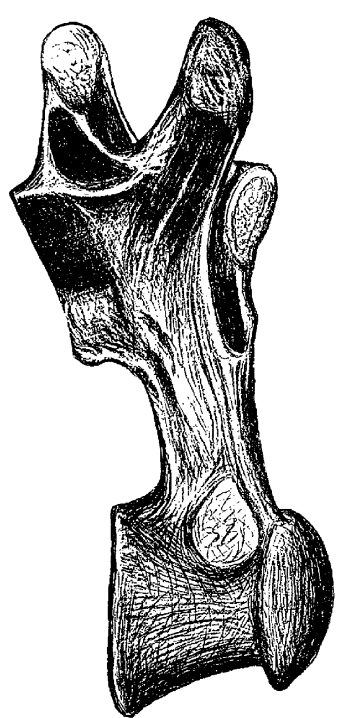

\footnotetext{
"The second sending included a number of vertebræ, which apparently represent a much more gigantic animal, and I believe the largest or must bulky animal capable of progression on land, of which we have any knowledge. This reptile I described in my palæontological bulletin No. 26, under the name of Camarasaurus supremus." From “On the Saurians Recently Discovered in the Dakota Beds of Colorado" by E. D. Cope (The American Naturalist, 1878, 12:71-85).
} 